\title{
Autodetermination in Microeconomics
}

\section{A Methodological Case Study on the Theory of Demand}

\author{
Prof. Dr. Olaf L. Müller (Humboldt-Universität zu Berlin)
}

\section{Contents}

I. Introduction — II. Individualistic, aggregated or idealized? -

III. A tautology and its Giffenesque message - IV. In search of an explanation - V. Two obstacles - VI. Explanations from common sense - VII. Maximizing behavior and the principle of charity - VIII. Preferences, presents, pyrotechnics - and a problem IX. A theoretical superstructure - X. From isolated tautologies to empirical holism XI. Criticizing theory or criticizing reality? - XII. An excursion into autodetermination in physics - XIII. Microeconomics as a synthesis of norms and descriptions - Literature

\begin{abstract}
My philosophical case study concerns textbook presentations of the theory of demand. Does this theory contain anything more than just a collection of tautologies? In order to determine its empirical content, it must be viewed holistically. But then, the theory implies false factual claims. We can avoid this result by embracing the theory's normative character. The resulting consequences will be illuminated with the new autodetermination thesis recently proposed in the philosophy of physics by Oliver Timmer. Applying his ideas to the theory of demand reveals that the statements of this discipline simultaneously concern both values and facts.
\end{abstract}

WARNING. This electronic version of the text is published here with kind permission of the publishing house Lucius \& Lucius, Stuttgart. It is not entirely identical with the most official version (see below): The electronic version differs from its official doppelganger typographically and with respect to quotation style. (The arguments, however, are the same in both versions). Here is how the paper has been published originally:

Olaf L. Müller: "Autodetermination in microeconomics. A methodological case study on the theory of demand". Analyse und Kritik 26 Heft 2 (Dezember 2004), pp. 319-345. 


\title{
Autodetermination in Microeconomics
}

\section{A Methodological Case Study on the Theory of Demand}

\author{
Prof. Dr. Olaf L. Müller (Humboldt-Universität zu Berlin)
}

\section{Introduction}

Economic thinking dominates our politics, our society and our lives more powerfully than ever before. Those who refuse to yield to economic arguments in political disputes are accused of being out of touch with reality: They simply fail to face up to the facts. ${ }^{1}$ How convincing is such an accusation? The answer to this question depends on whether economists practice something comparable to hard science. That is, it depends on whether economists deliver empirical statements about some aspect of reality, which are not only independent of their prejudices, hopes or political ambitions, but are also independent of their moral values and norms.

Surprisingly, whether or not this is the case is anything but clear. Our understanding of exactly how the science of economics works and what it actually achieves is modest as compared to the influence that economic thought exerts on all of us. A dangerous discrepancy has been developing.

In order to reduce this discrepancy, we must examine different areas of economists' scientific reasoning. This is an enormous task, which can only be handled one step at a time. I will concentrate my methodological reflections on a

1 Here is a typical citation from economics that illustrates this view: "There is hardly any doubt that most value judgments that are expressed on social questions are [...] perfectly amenable to 
small, but prominent fragment of microeconomics, ${ }^{2}$ which can be presented easily, and which is usually handled early on in the study of economics: The theory of the dependency of demand for commodities on price and income. ${ }^{3}$

At first glance, central parts of this theory do not provide any information about observable reality at all. As we shall see, either they are tautological, or they concern things that cannot be grasped in empirical reality. We can remedy this flaw by considering the theory as a whole, i.e. holistically. By doing so, our theory gains empirical content, but unfortunately, too much of it. Its empirical consequences are false.

Many methodological considerations of economic theory run into similar difficulties. ${ }^{4}$ Instead of a scholarly discussion of the received views, at the end of this essay I would like to sketch a novel proposal for escaping the dilemma of either being empirically empty or empirically false. My suggestion ties in with a recent consideration from the philosophy of physics, according to which physical theories determine by themselves what they are about. Sometimes physicists have first to manufacture the intended domain of their theory. Once this bold idea is applied to our microeconomic theory, something surprising results. When microeconomists want to create the intended domain of their theory, they can only do it normatively. They have to convince people to accept the rational norms postulated by their theory.

If they succeed, then the theory turns out to be empirically correct. If they continue to fail, then the theory is not conclusively empirically refuted, but its research program has failed to establish itself. In short, the empirical success of the microeconomic theory under consideration is inseparably related to its normative success. This is the basic idea of the proposal that I will introduce in this essay (without developing or thoroughly defending it).

But first a warning: Although it is only a tentative proposal, I will not always provide the required reservations, and I am aware that further discussion could

the attempt to influence values by persuading the parties holding them that the facts are other than what they believe them to be" (Blaug [MoEH]:116).

2 Although we shall be dealing with a fragment of microeconomic theory, for the sake of brevity, I shall simply call it a "theory" throughout the present essay.

3 I will base my case study on the following presentation of the relevant theory: Varian [IM]:1156, Varian [MA]:94-139, Kreps [CiMT]:17-63, Deaton et al [ECB]:3-82. 
sweep it from the table. If that does not happen, and if my proposal can also be applied to other areas of economics (which I cannot further discuss here), then we have every reason to reconsider talk of hard economic facts. Indeed, economic facts are dependent on normative decisions that we can make for ourselves. Our political options might thereby be expanded.

\section{Individualistic, aggregated or idealized?}

Our microeconomic theory is about the dependency of the demand (for any kind of commodity) on price and income. One of its typical questions is this:

(1) If $\mathrm{x}_{0}$ units of a commodity $\mathrm{C}_{0}$ and $\mathrm{x}_{1}$ units of a commodity $\mathrm{C}_{1}$ are purchased - how does the demand for quantities change as the price $\mathrm{P}_{0}$ of the first commodity drops, while $\mathrm{P}_{1}$ and the disposable budget $\mathrm{B}$ remain unchanged?

Even this harmless question does not, by itself, have contact to reality. It does not specify at whose purchasing behavior it is aimed. Does it aim at capturing the purchasing behavior of a single concrete person, or of most people, or of everyone? (These are three different readings of an individualistic approach). Does it attempt to capture the average purchasing behavior of a reasonably homogenous group of people, as for example forty-year-old school teachers in Scottish cities? (That would be an aggregated approach). Or does it aim at a mere thought-construction, as for example some kind of perfect (ideally informed, rational) individual? (That would be an idealized approach).

Whoever looks closely at contemporary microeconomic textbooks will not find homogeneous information about the intended area of application of the theoretical considerations developed. The authors even switch back and forth between individualistic, aggregated and idealized approaches in the midst of their considerations. ${ }^{5}$ This lack of consistency may serve the author's didactic purposes (for instance, by beginning with idealized considerations, and then illustrating these with aggregated examples from practice). If, by contrast, we pursue

4 Thus, Rosenberg speaks of the "Scylla and Charybdis of falsity or tautology" ([EMPS]:160).

5 The idealized character of our theory is seldom more clearly pronounced than as in Samuelson: "[...] we consider a single idealized consumer buying goods" ([FoEA]:96). Authors such as Varian develop their presentation of the theory in a similar spirit and then come up with examples from practice in which many consumers are suddenly considered on average, see e.g. Varian [IM]:67-69. Varian is aware of the problems that result from aggregation, see [IM]:84, $88,262$. 
philosophical aims and are interested in our theory's relation to reality, then at some point, we must decide whether it is supposed to be about individuals, groups or idealized constructions.

At first glance, the last-mentioned possibility offers our theory the smallest chance of stating something empirically testable about actual reality. By definition, idealized constructions do not occur in reality. Therefore, we should only draw on idealized constructions if all other options are closed. At the end of this essay, we will come to this point. As we shall see, idealized, normative considerations open new ways for understanding the methods of economic theory. Before we reach this conclusion, I will treat the theory in question on the basis of the individualistic approach in its most attractive version; that is, in the version that makes the theory's empirical application especially simple. Depending on the context, the theory will either be about at least one individual or about the majority of individual economic subjects. I will touch on the on-average, aggregated considerations only in the footnotes. They create quite a lot of complications, without delivering many philosophical results. In addition, they do not normally appear in actual developments of our theory. ${ }^{6}$

\section{A tautology and its Giffenesque message}

Thus, for the time being, let us consider a single economic subject S. ${ }^{7}$ For $\mathrm{S}$, the reader is invited to imagine one of her friends. With that, we return to our original question, and make it more concrete in light of what has already been said:

(2) How does S change her purchasing behavior, if the only change in her situation is that the price of the commodity $\mathrm{C}_{0}$ falls?

If you briefly think through the question with good common sense, then you will be doubly surprised at the answer that our microeconomic theory offers:

6 Even today, it remains all but clear how the individualistic standard model can be exploited in order to succeed in making empirical claims about groups of individuals. Deaton and Muellbauer correctly remind us that one may not simply assume that aggregated data from practice describe an individual who behaves according to the theory (see [ECB]:80/1, compare 148ff).

7 Naturally, this does not meet with every economist's tastes. For example, Hicks writes: “[...] economics is not in the end very much interested in the behavior of single individuals" ([VC]:34). Rosenberg criticizes this stance ([EMPS]:62, 159f et passim); see also Puu [SRoR]:102. How large the gap between our theory and real, aggregated data drawn from practice is, has been demonstrated by Blaug, see $[\mathrm{MoEH}]: 144 \mathrm{ff}$, and the literature that he provides. 
(3) If the price of every other commodity $\mathrm{C}_{1}, \ldots, \mathrm{C}_{\mathrm{n}}$ remains constant while the price of one commodity $\mathrm{C}_{0}$ falls, then the subject's demand for commodity $\mathrm{C}_{0}$ rises or falls (provided that the subject has access to constant budget B).

At first glance, this answer is surprising because it does not say anything at all. It is a tautology, ${ }^{8}$ and thus it is as useless as the following empty claim:

Tomorrow, either the weather will change, or it will stay the same.

It is not a criticism of a theory that uninteresting propositions such as (3) or (3') follow from it. Every tautology follows logically from any theory. Thus for example, proposition (3) follows from Newtonian mechanics. As many interesting truths can be drawn from such theories, they remain philosophically respectable. Consequently, we must consider whether we can extract sentences from our microeconomic theory that, in contrast to (3), contain interesting information. ${ }^{9}$

In order to discuss this, for a while I will continue to focus on isolated parts of our theory, and I will begin in this section with the two components of tautology (3). Later on, I will increase the scope and consider the theory in its entirety. As we shall see, empirical content only emerges from such a holistic approach (see section $\mathrm{X})$.

Let us look more closely at tautology (3). It does not claim anything interesting about the world because it expresses a complete disjunction. By itself, however, either arm of the disjunction is undoubtedly interesting.

S's demand for commodity $\mathrm{C}_{0}$ rises. ${ }^{10}$

8 A small correction is necessary. As it is formulated in the text, statement (3) at least excludes the possibility that the demand for commodity $\mathrm{C}_{0}$ does not change at all. However, it was certainly not the microeconomists's intention to declare that exactly an invariant demand for commodity $\mathrm{C}_{0}$ is impossible. Therefore, we are not doing violence to their claim when we read the term "rises" in (3) generously as "rises or remains the same". According to this reading, (3) is really tautological.

9 I am, of course, not the first to be concerned with this question. Varian also considers the issue in Varian [IM]:105/6. Varian answers the question in the chapter about revealed preferences and in the chapter about the Slutsky equation ([IM]:117-156). I will proceed more slowly than Varian, dwelling longer on the unobservable part of our theory and postponing my discussion of its actually testable consequences until sections IX and X.

10 This is the original (and in aggregated form, empirically quite well confirmed, see Blaug $[\mathrm{MoEH}]: 145 / 6)$ law of demand, in which economists were interested before they realized that they could not derive it exactly from their axioms (see Samuelson [FoEA]:115). But even this law was not immune to philosophical criticism. Hans Albert criticized the law first and 
S's demand for commodity $\mathrm{C}_{0}$ falls.

Sentence (3a) expresses a non-tautological, but unsurprising, relationship, with which we are well acquainted from our own experiences. The price of Kiwis falls, therefore our consumption of Kiwis increases. By contrast, the real surprise is offered by (3b). Although the price of $\mathrm{C}_{0}$ has fallen, $\mathrm{S}$ purchases a smaller amount of this commodity. In economics, commodities with this bizarre property are called Giffen goods. ${ }^{11}$

Perhaps it is the existence of such bizarre commodities that is the actual information conveyed by statement (3). That was the reason why I called it doubly surprising. According to its wording, statement (3) contains no interesting information (that was the first surprise). However, on account of its effects on an intelligent reader, (3) is nevertheless interesting (that was the second surprise). In order to make the truly interesting content of (3) explicit, the sentence should be reformulated as follows:

(4) Suppose that the price of some commodity $\mathrm{C}_{0}$ is falling. Then it is possible that a subject's demand (given a constant budget B) will fall for that very commodity $\mathrm{C}_{0}$, if the prices of the other commodities do not change.

And so as to avoid undue concerns about the metaphysical status of mere possibilities, we will even risk the following paraphrase:

(5) There is a commodity $\mathrm{C}_{\mathrm{i}}$, for which it holds that a subject's demand (given a constant budget $B$ ) for $\mathrm{C}_{\mathrm{i}}$ falls when the price of $\mathrm{C}_{\mathrm{i}}$ falls (while the prices of the other commodities do not change).

The justification for this otherwise prohibited transition from mere possibility to actual existence is that we were not exposed to the modal operator in (4) as a purely logical possibility, but rather as a real economical possibility, such as "in business, it can happen that" in the sense of "sometimes ..."

foremost because of its use of ceteris paribus clauses ([MP]:411/2). In my view, this criticism goes too far, because ceteris paribus clauses create philosophical problems outside of economics, and even in physics, compare Putnam [MFoR]:8-11. (I will mention the new law of demand in section X, near sentence (24), see the footnote there).

11 Regardless of what the name may suggest, the point does not appear to have been introduced into the debate by Robert Giffen, but by Marshall, see Blaug [MoEH]:140. 


\section{In search of an explanation}

Let us assume that sentence (5) provides the truly intended content of our unfortunate tautology (3). The question arises: Can sentence (5) be empirically supported? The answer is yes. We have to find a commodity of which our subject $\mathrm{S}$ demands less, the cheaper it is offered. In order to verify empirically sentence (5), a single example of a Giffen good is sufficient. From my own experience, I know an array of tea-drinking subjects $\mathrm{S}$, for whom:

(6) When the price of Yunnan tea declines, S can more often afford a good Darjeeling, so that in total S drinks less Yunnan tea.

In short, sentence (5), which is the genuine point that we drew from tautology (3), does not only have empirical content (and is thus interesting), it is also empirically confirmed, and thus true. ${ }^{12}$

But what do sentences like (6) have to do with microeconomics? Even without any prior knowledge of microeconomic theory, I could have formulated an empirically verified sentence like (6). Anyone who wants to compare the methodology of microeconomics with that of physics will presume that our microeconomic theory explains a sentence like (6). But what does that mean? In our case, it might mean that the truth of (6) can be deduced from the theoretical assumptions (axioms) advanced by our microeconomic theory. The assumptions that come into question for this purpose are:

(7a) The subject $\mathrm{S}$ has an intrinsic ${ }^{13}$ preference ordering over the set of all bundles of commodities. This preference ordering does not change during price reductions.

(7b) This preference ordering is continuous, monotonic, and strictly convex.

(7c) S will always buy the bundle of commodities that she prefers over all other bundles within the limits of her budget.

12 Naturally, it is easier to prove the existence of Giffen goods with an individualistic approach than with an aggregated approach. In the first case, a single subject who acts as described is sufficient. In the second case, sufficiently many individuals of the group under consideration must behave appropriately, and they must do so with respect to one and the same good. When microeconomists write that Giffen goods have not yet been observed and that their existence is improbable (e.g. Varian [IM]:107, Kreps [CiMT]:61), they are apparently adopting an aggregated approach. (And that, although e.g. Kreps speaks of $a$ consumer in the same breath!) Thereby, they exacerbate the theory's relation to reality. (For more on the probability of Giffen goods, see Blaug [MoEH]:148/9 and, in greater detail, Lipsey et al [CtNT]:148-159).

13 I call preferences that an economic subject can have between commodities "intrinsic" if they are independent from external factors such as price or income. 
At the moment, we do not need to worry about whether these theoretical assumptions are true, empirically verifiable, or tautological. We will return to this issue. Here, the only interesting question is: Do (7a)-(7c) explain the truth of (6)? I.e., do they imply sentence (6)?

The answer is no. Not every preference ordering that is permitted by (7a) and (7b), leads, by way of the maximization rule (7c), to the existence of Giffen goods. On the other hand, (7a)-(7c) do not exclude the possibility of Giffen goods either. However, that is too little. The axioms of Newtonian mechanics equally do not exclude the possibility of Giffen goods.

The comparison to Newtonian mechanics reveals the direction we must pursue in order to make headway in our explication. Just as axioms (7a)-(7c) do not contain the existence of Giffen goods, the axioms of Newtonian mechanics do not contain the existence of objects that fall with an acceleration of $g=9.81 \mathrm{~m} / \mathrm{s}^{2}$.

In both cases, we need more than just axioms. We also need initial conditions. In the case of mechanics, we need, for example, statements about an object with the mass of the Earth and about all kinds of objects with comparatively less mass. Which initial conditions do we need in order to explain, for example, that a particular commodity $\mathrm{C}_{0}$ such as Yunnan tea is a Giffen good?

If our microeconomic theory is at all helpful in finding the desired initial conditions, then the help can only come from the Slutsky equation. The result of this equation is that any commodity $\mathrm{C}_{0}$ is a Giffen good if and only if:

$$
\partial \mathrm{x}_{0} \mathrm{U} / \partial \mathrm{P}_{0}>\left(\partial \mathrm{x}_{0}^{\mathrm{B}} / \partial \mathrm{B}\right) \mathrm{x}_{0} \cdot{ }^{14}
$$

This equation compares the partial derivative of two functions with one another; namely that of the Marshallian demand function $\mathrm{x}_{0} \mathrm{~B}$ with that of the Hicksian demand function $\mathrm{x}_{0} \mathrm{U}$.

The Marshallian demand $\mathrm{x}_{0} \mathrm{~B}=\mathrm{x}_{0}(\mathrm{~B}, \mathrm{P})$ states which quantities $\mathrm{x}_{0}$ of the commodity $\mathrm{C}_{0}$ are demanded by the subject $\mathrm{S}$, if $\mathrm{S}$ has budget $\mathrm{B}$ at her disposal, and if the commodities $\mathrm{C}_{0}, \ldots, \mathrm{C}_{\mathrm{n}}$ cost exactly prices $\left(\mathrm{P}_{0}, \ldots, \mathrm{P}_{\mathrm{n}}\right)=\mathrm{P} .{ }^{15}$

14 See e.g. Deaton et al [ECB]:45/6 and Kreps [CiMT]:61. 
By contrast, the Hicksian demand $\mathrm{x}_{0} \mathrm{U}=\mathrm{x}_{0}(\mathrm{U}, \mathrm{P})$ is defined independently of the disposable budget. Instead, it is assumed that the subject wants to reach a certain utility level $\mathrm{U}$, and at given prices $\left(\mathrm{P}_{0}, \ldots, \mathrm{P}_{\mathrm{n}}\right)=\mathrm{P}$, wants to spend as little money as possible for the commodities to be acquired. There are various bundles of commodities, $\left(a_{0}, \ldots, a_{n}\right),\left(b_{0}, \ldots, b_{n}\right)$ etc., that yield the same utility level $U$ (so that our subject is intrinsically indifferent between all of these bundles). Now among these bundles there is just one bundle $\left(\mathrm{x}_{0}, \ldots, \mathrm{x}_{\mathrm{n}}\right)$ that will cost exactly as little as possible. The Hicksian demand function identifies this cheapest bundle, and in our case, tells us how many units $\mathrm{x}_{0}$ of the commodity $\mathrm{C}_{0}$ occur therein. ${ }^{16}$

Thus, in order to explain or predict that

For S, Yunnan tea is a Giffen good,

we must first determine the Hicksian and the Marshallian demand functions for Yunnan tea. Then, we have partially to differentiate these functions, and ultimately to calculate whether the following inequality holds:

$$
\partial \mathrm{x}_{0} \mathrm{U} / \partial \mathrm{P}_{0}>\left(\partial \mathrm{x}_{0} \mathrm{~B} / \partial \mathrm{B}\right) \mathrm{x}_{0}
$$

\section{Two obstacles}

Two obstacles hinder our attempt to explain sentence (8). While the first is a harmless pseudo-obstacle, the second is insurmountable. We will begin with the pseudo-obstacle. One could claim that our attempt to explain (8) with (7d) is circular.

In order to evaluate the right-hand side of (7d), we must know the Marshallian demand function. This implies that we already command a complete overview of the demand for Yunnan tea, subject to size of budget and price of all commodities. However, if we already command such a complete overview of the dependence of the demand for Yunnan tea on budget and all prices, then of course we already know how the demand for Yunnan tea changes subject to its price, if the budget and price of all other commodities remain invariant. In brief,

\footnotetext{
15 See e.g. Deaton et al [ECB]:15, 37.

16 See e.g. Deaton et al [ECB]:37.
} 
in order to use (7d) to explain (or to predict) that Yunnan tea is a Giffen good, we must establish the Marshallian demand, and this involves ascertaining whether Yunnan tea is a Giffen good. But an explanation that appeals to knowledge of the explanandum does not explain anything at all.

However, this charge of circularity misses its mark. Here is why. In order to determine (7d), we do not need the Marshallian demand function in its entirety, subject to dependence on budget and all prices. We simply need it as a punctuated function of the one variable that will be partially differentiated in (7d). Thus, we merely need it as a function of budget $\mathrm{B}$. This functional relationship can be empirically ascertained without having to presuppose knowledge about the explanandum. One simply measures the income/consumption curve, which for the time being, has nothing to do with the case of Giffen goods. With that, the harmless pseudo-obstacle that at first appeared to hinder explaining (8) with (7d) is removed.

By contrast, the following obstacle is insurmountable. In order to complete our evaluation of (7d) on the left-hand side, we depend upon the Hicksian demand function for Yunnan tea. According to textbooks, this function cannot be empirically ascertained at all. ${ }^{17}$

Let us briefly clarify why this is the case. At first glance, it is because the utility level $U$ cannot be quantitatively measured in empirical reality. ${ }^{18}$ (From the axioms of our microeconomic theory, the existence of utility functions can be deduced (Varian [MA]:97). However, they are only unique up to monotonic transformations (Varian [IM]:57)).

Once again, we just need the result of the left-hand side of our inequality (7d). We do not need the complete Hicksian demand function. For our purposes, its partial derivative with respect to the price variable $\mathrm{P}_{0}$ of the commodity $\mathrm{C}_{0}$ is sufficient, and we need the value of this calculation only at that point where our subjects is confronted with a price reduction. The price vector is completely known to us, and while we cannot quantitatively specify the resulting utility level uniquely, we can indeed qualitatively capture it, by claiming that: "We determine

17 Thus e.g. Kreps [CiMT]:58, Varian [MA]:105.

18 See Kreps [CiMT]:58, Varian [MA]:105. 
the Hicksian demand function (for the purpose of partial differentiation) on that utility level at which the subject is when she has exactly the bundle of commodities $\left(\mathrm{a}_{0}, \ldots, \mathrm{a}_{\mathrm{n}}\right)=\mathrm{x}(\mathrm{B}, \mathrm{P})$ at her disposal."19

But even then, we still do not make progress, since we must consider which cheaper bundle $\left(\mathrm{x}_{0}, \ldots, \mathrm{x}_{\mathrm{n}}\right)$ the subject chooses, in place of $\left(\mathrm{a}_{0}, \ldots, \mathrm{a}_{\mathrm{n}}\right)$, without thereby improving or worsening her situation. Indeed we can observe which bundle the subject chooses, given a certain budget and set of prices, but that would only be the Marshallian demand function. We cannot observe what the subject would choose, if she desired to stay at the same utility level as she would be with $\left(\mathrm{a}_{0}, \ldots, \mathrm{a}_{\mathrm{n}}\right)$ while spending as little as possible to accomplish this task. We cannot observe this because all observable purchasing decisions occur given fixed budget specifications. It is not possible to hypothetically stipulate away the subject's budget, and at the same time, to intend to make a real observation.

And even if this hybrid hypothetical-factual observation were possible, there would still be another problem. Even then, we could not, on the basis of observations, know whether the subject was really intrinsically indifferent between the bundle chosen and the original bundle. How can one observe indifference, when the subject explicitly decides? ${ }^{20}$ If we could look directly into the subject's mind and examine the preferences and indifferences there, then no difficulty would arise. However, as things stand, the preferences and indifferences of the subject are not directly accessible. ${ }^{21}$

19 In this connection, $\mathrm{x}_{0}(\mathrm{~B}, \mathrm{P})$ is again the Marshallian demand function, as above elucidated. The suggestion between quotation marks thus amounts to the suggestion to free the Hicksian demand from the quantitative contingencies of the utility function. Instead one should replace the Hicksian demand function $\mathrm{x}_{0}(U, \mathrm{P})$, given a level of utility $\mathrm{U}$, in favor of an equivalent function $\mathrm{x}_{0}\left(\left(a_{0}, \ldots, a_{n}\right), \mathrm{P}\right)$, given commodity $\left(\mathrm{a}_{0}, \ldots, \mathrm{a}_{\mathrm{n}}\right)$, and then partially differentiate with respect to $\mathrm{P}_{0}$.

20 The observation of indifference creates intricate problems that Sen very convincingly discusses (Sen [BCoP]:61/2). I would like to supplement his considerations with two remarks. (i) It is not coherent when microeconomists provide plenty of (intrinsic) indifference curves (e.g. Varian [IM]:36-52 et passim) and at the same time insist on the fact that in every situation there is just one optimal option (in order to maintain the subject's capacity to act). (ii) If at all, then one should try it the other way around. I think that one could grasp indifference in purchase decisions, at least in principle: One produces one hundred copies of our subject S. If, in a concrete purchasing situation, fifty copies decide for one commodity and fifty copies decide for the other, then the original subject $\mathrm{S}$ is indifferent. Which option $\mathrm{S}$ chooses would then depend on chance, so to speak. (Kreps also draws on duplicated economic subjects, although in another context, see Kreps [CiMT]:50).

21 I will defend this claim later in more detail, see section VIII. It can be traced back to Samuelson (see e.g. [NoPT]:61) and is usually not well justified in the textbooks (see e.g. 
Put succinctly, we cannot measure the limited Hicksian demand function that we want partially to differentiate in the left-hand side of (7d). Consequently, with the help of equation (7d), we are unable to explain that, for example, Yunnan tea is a Giffen good for some subject. ${ }^{22}$

Successful explanations of a single fact consist of a general law and special initial conditions (whose truth can be established independently of the explanandum); the explanandum succeeds just in case these initial conditions, together with the general law, logically (or probabilistically) imply the truth of the explanandum. ${ }^{23}$ Applied to our case, we have attempted a failed explanation with the following general law:

(9) A commodity $\mathrm{C}_{\mathrm{i}}$ is a Giffen good if and only if:

$$
\partial \mathrm{x}_{\mathrm{i}}^{\mathrm{U}} / \partial \mathrm{p}_{\mathrm{i}}>\left(\partial \mathrm{x}_{\mathrm{i}}^{\mathrm{B}} / \partial \mathrm{B}\right) \mathrm{x}_{\mathrm{i}}
$$

Our explanandum claims:

Yunnan tea is a Giffen good.

The initial conditions that we would need in order to explain this explanandum would be:

(10) For the commodity $\mathrm{C}_{0}$ (Yunnan tea), it holds that:

$$
\partial \mathrm{x}_{0} \mathrm{U} / \partial \mathrm{P}_{0}>\left(\partial \mathrm{x}_{0}^{\mathrm{B}} / \partial \mathrm{B}\right) \mathrm{x}_{0} \text {. }
$$

And we have failed to guarantee empirically that these initial conditions actually hold.

Varian [IM]:117). Sen defies this prevalent consensus; he insists on introspection and communication (Sen [BCoP]:71/2). On this point, I do not share Sen's optimism. He does not take into account Wittgenstein's private language argument (compare Wittgenstein $[\mathrm{PU}]: \S 243 \mathrm{ff})$.

22 It can easily be shown that matters will not improve when we change from an individualistic to an aggregated approach. The Hicksian demand function cannot be empirically better grasped by increasing the number of subjects.

23 The locus classicus for this view of explanation is Hempel / Oppenheim [SiLo]. I have drawn on their view because it is especially simple. Those who prefer more sophisticated models of explanation can easily appreciate that the problems that I have raised will also apply to their models. 


\section{Explanations from common sense}

After the distressing result of the last section, the question arises: How can we explain that Yunnan tea is a Giffen good for certain tea drinkers? Are we perhaps dealing with a completely inexplicable fact? - Luckily, we are not. Here is a suggestion for what I take to be a halfway successful explanation. General law:

(11) For all commodities $\mathrm{C}_{\mathrm{i}}$ and all subjects $\mathrm{S}$, it holds that: Commodity $\mathrm{C}_{\mathrm{i}}$ is always a Giffen good for a subject $\mathrm{S}$, if there is a more expensive good $\mathrm{C}_{j}$ for which it holds that:

$\mathrm{C}_{\mathrm{i}}$ and $\mathrm{C}_{\mathrm{j}}$ serve $\mathrm{S}$ by satisfying one and the same type of need. With respect to quantity, $\mathrm{S}$ always wants to satisfy this need to the same extent, but $\mathrm{S}$ would rather satisfy this need with $C_{j}$ than with $C_{i}$.

Initial condition:

(12) The tea drinkers in question like to drink six cups of tea each day and they prefer Darjeeling tea to Yunnan tea; Darjeeling tea is more expensive than Yunnan tea.

From (11) and (12) it follows that Yunnan tea is a Giffen good for these tea drinkers. ${ }^{24}$

I admit that my explanation sounds more like common sense than like real scientific theory. I am also afraid that the supposedly general law (11) turns out to be false. (At least this shows that it has empirical content). But still, the explanation makes the reaction of a tea drinker to falling Yunnan tea prices more understandable than inapplicable models such as (9)-(10).

I would like to dwell briefly on the question of what my common sense explanation has to do with economic theory. Interestingly enough, in his textbook Intermediate Microeconomics, Varian appeals to quite similar common sense considerations in order to make the case of Giffen goods intuitively plausible ([IM]:104/5). Later, Varian relies on the mathematical weaponry of the Slutsky equation, and derivates a result similar to the condition in (7d) for Giffen goods ([IM]:142/3). ${ }^{25}$ What I am wondering, and what I would like to see discussed, is the following: Would it have been plausible without intuitive considerations à la

24 Varian argues along similar lines (but with different examples), see [IM]:104/5, [MA]:117/8.

25 Anyway almost; in order not to make it unnecessarily difficult for his readers, Varian does not implement this consideration in that textbook with completely developed methods of differential calculus (see [IM]:XX). 
(11) and (12), that the completely abstract inequality in (7d) were ever true? If not, then mathematical models in the economic literature would not carry the real burden of explanation for the case of Giffen goods. Instead, common sense alone would carry the real explanatory burden. ${ }^{26}$

One might object that the microeconomic theorem

$$
\begin{aligned}
& \text { A commodity } \mathrm{C}_{\mathrm{i}} \text { is a Giffen good if and only if } \\
& \partial \mathrm{x}_{\mathrm{i}}^{\mathrm{U}} / \partial \mathrm{p}_{\mathrm{i}}>\left(\partial \mathrm{x}_{\mathrm{i}}^{\mathrm{B}} / \partial \mathrm{B}\right) \mathrm{x}_{\mathrm{i}},
\end{aligned}
$$

was never intended to help explain or predict which commodities are Giffen goods (together with empirical initial conditions). Instead, the objection goes, our theorem (9) concerns the formulation of a theoretical condition for the occurrence of Giffen goods. ${ }^{27}$ In light of this objection, I wish merely to raise (though not discuss) two questions. First, what good are such theoretical conditions? Second, are there (e.g. in physics) comparable conditions that should be necessary for the existence of some observable facts, without it being empirically possible to show that they hold?

\section{Maximizing behavior and the principle of charity}

In the last two sections, we hit a dead end. Our microeconomic theory does not say anything informative about Giffen goods. It made us aware of their possible existence (which perhaps had never occurred to us), but the theory does not offer anything to help us understand this possibility. Put another way, Giffen goods do not provide the theory with an empirical connection to the world. Does that mean

26 The following question arises: Could we not transform our common sense explanation into the regimented form of a real economic theory? Yes. However for that, one would need finer conceptual tools (instead of the vague concepts such as "type of needs to be satisfied"). This could be accomplished, for example, by postulating that different commodities can have one and the same "character" (even if they have that "character" to different extents per unit of quantity). See Lipsey et al [CtNT]:133ff.

27 The objection was suggested by an anonymous referee. Here is a source of information that fits to this objection: "[The] Hicksian demand function is based on Hicksian compensation. Actually making Hicksian compensation is not going to be possible because it depends on the unobservable utility function; it is meant solely as a theoretical construct" (Kreps [CiMT]:58, my italics). Then Kreps proves the Slutsky equation ([CiMT]:59), and with an appropriately bad conscience, as he writes in brackets: "You may be wondering where all this is headed. We are certainly taking lots of derivatives, and it isn't at all clear to what end we are doing so. Some results are coming [...]. Please be patient" ([CiMT]:59). Two pages later he introduces the promised result as follows: "Of what use is this?" ([CiMT]:61) and he answers his rhetorical question with considerations in which he makes uncritical use of purely theoretical 
that the entire theory delivers as little as the Slutsky equation? That has not yet been shown. It could be that the Slutsky equation is a by-product of a theory that elsewhere performs useful empirical functions. In order to check whether this is the case, I will focus on two of the key ideas of the theory. In this section, I will examine the idea of maximizing behavior, and in the following section, I will examine the concept of preference.

Let us begin with the conception of maximizing behavior, that is, with the assumption that every economic subject always chooses the bundle of commodities that she prefers over all other available bundles. This assumption cannot be tested empirically, because in order to test it, we would need to know which bundle the subject prefers over all of the others. This, in turn, can only be determined if we assume that the subject orients her behavior toward the ideal of maximization. That is to say, we will always attribute to the subject those preferences that allow her choice of behavior to appear optimized. For this reason, we would not accept a claim such as:

(13) She prefers red wine to white wine. But whenever both are readily available, she drinks white wine.

Rather, we would say:

(14) She prefers white wine to red wine. This follows from the fact that she always drinks white wine when both are readily available.

In short, the thesis of maximizing behavior is not empirically confirmable or falsifiable. It is a regulative principle that we must presuppose whenever we describe decisions with the help of preferences. ${ }^{28}$

Hicksian demand! (The first of these considerations refers to Giffen goods and is equivalent to my account above in the text, see [CiMT]:61).

28 I support this argument with a consideration from the philosophy of language, where one often draws on "the principle of charity": According to the principle, one should avoid ascribing someone with excessively absurd opinions; instead, one should reinterpret her words if need be. (For example if someone were to say: "Look a giraffe" while standing in front of an elephant, the principle recommends assuming that she learned the words incorrectly, instead of assuming that she really means that she is standing in front of a giraffe). The result of transferring this principle to our case is: One should avoid ascribing someone with so much irrationality that she is always acting against her preferences. - For the orthodox version of the principle, compare e.g. Quine [WO]:58/9 and Davidson [RI]:137. I have tried to make the principle fruitful for ethics by transferring it to various types of speech acts (instead of propositional content), see Müller [CTSW] and [AEE]. 


\section{Preferences, presents, pyrotechnics - and a problem}

Our next questions is: Under the assumption that our subject follows the rule of maximization, can we observe which bundles of commodities the subject prefers over the others? I will suggest a test-procedure that appears to allow for a direct measurement of preferences. In order to meet several (relatively insignificant) objections, certain modifications will be necessary. While these modifications seem to make the test-procedure somewhat bizarre, they do not spoil its philosophical worth. At the end of the section, however, I will raise what I consider to be the most decisive objection against the proposed test-procedure.

How can we determine whether a subject prefers commodity $\mathrm{x}$ to commodity $\mathrm{y}$ ? Simply asking which commodity she prefers will not do. She could mislead us, or even herself. Her answers to our questions only provide empirical evidence about how the subject responds to certain questions. It does not provide reliable evidence that her preferences really are what she claims them to be. Given that simply asking a subject is insufficient for determining her true preference, perhaps we could provide a choice between the commodities in question, and then simply observe what she actually decides?

This will not work either. For example, let us assume that we want to find out whether the subject prefers 30 kiwis and 2 carrots to 2 kiwis and 30 carrots. We could give her a voucher with which she can choose between one of these two bundles of commodities. Even if the subject were to use her voucher to obtain the kiwi-rich set of commodities, we still cannot infer that she prefers 30 kiwis and 2 carrots to 2 kiwis and 30 carrots. This is because, as it turns out, the subject may already have a crate with 90 carrots in her kiwi-free kitchen. In such a case, we could conclude from our test no more than this:

(15) The subject prefers 30 kiwis and 92 carrots to 2 kiwis and 120 carrots.

And we do not even know this for sure, as the subject might have used the voucher to obtain the kiwi-rich bundle of commodities because she owns an ice cream machine and enough sugar to produce kiwi sorbet. In that case, the result of our voucher experiment would be:

(16) The subject prefers 30 kiwis, 92 carrots, 5 pounds of sugar and an ice cream machine to 2 kiwis, 120 carrots, 5 pounds of sugar and an ice cream machine. 
It is obvious that these considerations can be generalized for any kind of commodity available to our subject at the time of the test. Take $b=\left(b_{1}, \ldots b_{n}\right)$ to be the bundle in the possession of the subject at the time of the test. In this case, we could give her a voucher for the choice of either commodity $\mathrm{x}$ or $\mathrm{y}$; if, for instance, she decides for $\mathrm{x}$, then we conclude:

(17) The subject prefers $(x+b)$ to $(y+b)$.

Put negatively, this means that the voucher test does not provide any empirical conclusions about preferences ranging over bundles $\mathrm{z}$, for which there is no bundle $\mathrm{x}$ such that $\mathrm{z}=\mathrm{x}+\mathrm{b}$. So far, the preference relation (which according to microeconomic theory should be complete) can be empirically established only for a sub-range of the quantity of all pairs of bundles. ${ }^{29}$

Let us attempt a trickier experimental setup in order to overcome these limitations. We could begin by destroying the subject's inconvenient bundle b of commodities - for instance through arson. Thereafter, we could present her with a voucher that can be exchanged for either bundle $\mathrm{x}$ or bundle $\mathrm{y}$. If she were to exchange the voucher for commodity $\mathrm{x}$, then we would indeed know that she prefers $\mathrm{x}$ to $\mathrm{y}$. Next, we could destroy $\mathrm{x}$ (for instance, by burning just that room in which it is stored), and then provide a voucher for either $\mathrm{x}$ or $\mathrm{z}$, and so on.

Such an experiment may not be legally or economically feasible. After all, it is illegal and expensive to burn other people's property. However, these are not objections within our philosophical context. Neither money nor the law determine empirical testability, and thereby, scientific respectability.

Before moving on to my main objection against attempting to establish empirical meaning for our particular claims about preferences, I would like briefly to undermine another objection. This objection claims that the Burn-and-Voucher method can only be executed in a series of separate experiments, while the presupposed microeconomic preference ordering should be complete at any given point in time. ${ }^{30}$ I take this to be a mere practical consideration, which from a philosophical perspective, we do not need to worry about. In principle (if not

29 As can easily be shown, this is a different restriction on our knowledge of the preference relation than the restriction that emerges out of Samuelson's theory of revealed preferences (see Samuelson [CTiT], [PoIi] and Varian [IM]:117-134).

30 Sen raises a similar problem, see $\operatorname{Sen}[\mathrm{BCoP}]: 56 / 7$. 
technically), it would be possible, at the time of the experiment, to make as many exact copies of the subject that we need for the experiment, so that we can present each of them with one pair of bundles of commodities. ${ }^{31}$ By doing so, we could (if we really wanted to, and if it were technically possible) reach the desired experimental results all at once. In this way, claims about a temporally consistent preference ordering would obtain testable, empirical content - at least in principle.

Then why don't we find out the preferences of a test subject according to the proposed method, i.e. by arson and vouchers? In my view, the reason is this. If we were to deprive a person of all of her property, and then present her with various vouchers, we would change her (including her preferences) so dramatically, that the results cannot be transferred to normal purchase situations. Our experiment would tell us something about the typical decisions of individuals who had just lost all their property as the result of arson, and who consequently have to select between different gifts. However, we are interested in statements about individuals who do not select between gifts, but between goods for which they must pay.

\section{A theoretical superstructure}

If the considerations in the last section are correct, then we cannot directly observe an individual's preferences. The sentence

(18) At time $t$, the subject intrinsically prefers bundle $\mathrm{x}$ of commodities to bundle $y$,

has - taken by itself - no empirical meaning whatsoever. And the expression "intrinsic preference" does not represent an empirically observable relation that exists in the world. Instead, it is more like a theoretical term; we need not assume that theoretical terms refer to something that actually exists in the world. ${ }^{32}$ of course, such theoretical terms should not be used in complete isolation from

31 Just like in Kreps [CiMT]:50.

32 Puu very illuminatively discusses such a suggestion for macroeconomics in [SRoR]:102/3, 109-111. 
empirical reality. Their use is justifiable to the extent that they help organize our empirically collected data. ${ }^{33}$

Which empirical data could we organize with the help of the theoretical term "preference"? We could help organize data about purchasing decisions. In order to conduct an experiment in a small test-supermarket, we could observe (and even manipulate) the following parameters:

the prices $\left(\mathrm{P}_{0}, \ldots, \mathrm{P}_{\mathrm{n}}\right)=\mathrm{P}$ of commodities $\mathrm{C}_{0}, \ldots, \mathrm{C}_{\mathrm{n}}$; and

the budget $\mathrm{B}$ at the disposal of our subject.

According to the specifications of these parameters, we send our subject through the test-supermarket and record which commodities she buys in which amounts. We repeat the experiment for any price and budget. Each purchased bundle $\mathrm{x}$ of commodities thereby results as an empirical function of prices and budgets. This is the well-known Marshallian demand function (see section IV above):

$$
\mathrm{x}^{\mathrm{B}}=\mathrm{x}(\mathrm{B}, \mathrm{P})
$$

That would be the empirical part of our scientific work. After collecting these empirical data, we design a small theoretical superstructure. We say:

(20) The subject behaves as if she had a preference relation $\mathrm{R}$ (over the set of all bundles of commodities), for which it holds that:

(20a) $\mathrm{R}$ is reflexive, transitive, complete, continuous, monotonic and strictly convex.

(20b) For all commodities y with $\mathrm{P}_{1} \mathrm{y}_{1}+\ldots+\mathrm{P}_{\mathrm{n}} \mathrm{y}_{\mathrm{n}} \leq \mathrm{B}$ it holds that: $\mathrm{x}(\mathrm{B}, \mathrm{P}) \mathrm{R} \mathrm{y}$,

i.e. the actually purchased bundle of commodities is preferred to any bundle $y$ that the subject could have afforded given the scope of her budget.

However, this formulation still appeals too strongly to our everyday understanding of preferences. As from our present point of view the term "preference" should completely lack empirical applicability, we alter the

33 The advantage of being an organizing force does not apply to every term whose application criteria cannot be empirically specified: "ether wind", for example, or "fate" are negative cases. Positive cases are known, for example, from physics, such as "electron", "force", "magnetic field", etc. 
theoretical superstructure so that every association to parochial preferences is excluded:

(21) For every subject, there is a relation $\mathrm{R}$ over the set of all bundles of commodities, for which it holds that:

(21a) $\mathrm{R}$ is reflexive, transitive, complete, continuous, monotonic and strictly convex.

(21b) For all commodities y with $\mathrm{P}_{1} \mathrm{y}_{1}+\ldots+\mathrm{P}_{\mathrm{n}} \mathrm{y}_{\mathrm{n}} \leq \mathrm{B}$, it holds that:

$$
\mathrm{x}(\mathrm{B}, \mathrm{P}) \mathrm{R} \mathrm{y} \cdot{ }^{34}
$$

\section{$X$. From isolated tautologies to empirical holism}

We now want to consider whether the theoretical superstructure from the last section has a relationship to empirical reality, or whether its observable content is empty. We will proceed in three steps. In the first two steps, we will examine clauses (21a) and (21b) separately. As we shall see, considered in isolation, both clauses are tautologies. They remain true regardless of how the subject behaves, and so they do not make any claims about the world. It follows that they are not empirically falsifiable. After these first two distressing steps, we will consider both clauses in combination. Fortunately, taken together, they do indeed have empirical content, as they have empirically refutable consequences. As we shall see, we can formulate a scientifically respectable theory just by taking the two clauses together.

First, however, let us consider the two clauses in isolation. We begin with the second clause from (21). Removed from the context of (21), the clause runs as follows:

(22b) For the subject, there is a relation $\mathrm{R}$ over the set of all bundles of commodities, for which it holds that:

For all bundles y with $\mathrm{P}_{1} \mathrm{y}_{1}+\ldots+\mathrm{P}_{\mathrm{n}} \mathrm{y}_{\mathrm{n}} \leq \mathrm{B}$, it holds that:

$$
\mathrm{x}(\mathrm{B}, \mathrm{P}) \mathrm{R} \mathrm{y} \cdot{ }^{35}
$$

34 This transition from sentences like (20) with theoretical terms (here: "preference relation") to purely existential claims like (21) (in which the theoretical terms are replaced by bound variables) is known in the philosophy of science by the name of "Ramsification". One can prove that the Ramsification of a theoretical sentence has the same empirical consequences as the theoretical sentence itself. (A detailed discussion of Ramsification is provided by Stegmüller [TE]/1:400-37. The proof of empirical equivalence can be found on pp. 409-11). 
This is a tautology for logical reasons: It is a tautology because there is always some relation with the desired characteristics. For example, for $\mathrm{R}$ we could choose the trivial relation that holds between every pair of bundles of commodities. (22b) is guaranteed no matter how the subject behaves. In isolation from the entire context, the first clause from (21) is no better off:

(22a) For the subject, there is a reflexive, transitive, complete, continuous, monotonic and strictly convex relation $\mathrm{R}$ over the set of all bundles of commodities.

Sentence (22a) is not yet connected to empirical reality, as it does not mention any empirical factor that has something to do with the behavior of the subject at all. The part of the sentence that I have emphasized could just as well be left out, as it plays no role for the text that follows it. (That part of the sentence is as equally superfluous in (22a) as it is in the following sentence: "For the subject, there is a set with exactly 17 prime numbers"). Thus, instead of (22a), we get:

(22a') There is a reflexive, transitive, complete, continuous, monotonic and strictly convex relation $\mathrm{R}$ over the set of all bundles of commodities.

This is a mathematically true sentence. I.e., it is a sentence that is true in every possible world. Consequently, it cannot say anything interesting about this world. ${ }^{36}$

These two results feed the fear that our entire theoretical superstructure could be empirically empty, because a relation R, suitable for fulfilling (22a) or (22b), can always be found, regardless of how the subject behaves. To be less pessimistic, one could even turn this fear into something positive: No matter how idiotic someone behaves while shopping, we can deliver a rationalization that attributes maximizing behavior to the consumer in question. As nice as this may sound, it would be the end of microeconomics' claim to empirical content.

Fortunately, microeconomists do not need to make such a philosophical capitulation, because taken together, the two clauses (22a) and (22b) do have empirical content. How is this possible, if both are individually tautological? The

35 The term $\mathrm{x}(\mathrm{B}, \mathrm{P})$ again stands for the Marshallian demand function. By comparing (21b) and (22b) it becomes apparent that in (22b) an additional quantifier appears, which is missing in (21b). We need this additional quantifier in order to bind the variable $\mathrm{R}$ and thereby to construct the closed proposition (22b) out of the propositional function (21b). 
answer can be found in logic. A conjunction within the domain of an existential quantifier is logically stronger than the conjunction of the existence claims. (For example, "There are white horses" is stronger than "There are horse, and there are white objects"). This applies to our case as well. A stronger sentence results from combining the two clauses (22a) and (22b), which taken by themselves are tautological: 37

(21) For the subject, there is a relation $\mathrm{R}$ over the set of all bundles of commodities, for which it holds that:

(21a) $\mathrm{R}$ is reflexive, transitive, complete, continuous, monotonic and strictly convex.

(21b) For all commodities y with $\mathrm{P}_{1} \mathrm{y}_{1}+\ldots+\mathrm{P}_{\mathrm{n}} \mathrm{y}_{\mathrm{n}} \leq \mathrm{B}$, it holds that:

$$
\mathrm{x}(\mathrm{B}, \mathrm{P}) \mathrm{R} \mathrm{y} \text {. }
$$

I want to illustrate that this sentence involves at least two empirically refutable consequences. The first such consequence from (21) prohibits certain purchasing decisions, as for example:

(23) While purchasing tea, no subject $\mathrm{S}$ with a budget of $\$ 30$ will behave as follows:

(23a) if $100 \mathrm{~g}$ Darjeeling tea costs $\$ 12$ and $100 \mathrm{~g}$ Yunnan tea costs $\$ 6$, S buys 200g Darjeeling tea and 100g Yunnan tea, and

(23b) if $100 \mathrm{~g}$ Darjeeling tea costs $\$ 6$ and $100 \mathrm{~g}$ Yunnan tea costs $\$ 12$, S buys $100 \mathrm{~g}$ Darjeeling tea and $200 \mathrm{~g}$ Yunnan tea. ${ }^{38}$

36 To be very precise, there is some informative content in (22a) that is missing in (22a'): The existence of the subject. This minor point is irrelevant to my argument.

37 Quine says that these sentences, which taken individually are remote from observation (i.e. theoretical sentences), taken together reach "critical semantic mass", cf. [PoT]:17.

38 Similar examples can be found in Kreps [CiMT]:44 and in Varian [IM]:123/4. Varian's diagnosis of his example only offers half of the truth: "Clearly, this consumer cannot be a maximizing consumer" (Varian [IM]:124). What Varian forgets to mention is the holistic reference to the rest of the model's assumptions (such as reflexivity, transitivity, etc.) To repeat: Maximizing behavior by itself cannot be captured empirically in isolation from the rest of the model. Samuelson had the brilliant idea to transform the empirical content of ordinal utility theory completely into a system of statements of the form (23), see Samuelson [PoIi], especially pp. 369-372, compare Varian [IM]:124-129. In this version, his conception of revealed preferences shows that he was at the forefront of the philosophy of science of his time. The reductionism of his earlier conception (see Samuelson [CTiT]:243 et passim) became obsolete because of Quine's innovative plea for holism in science (compare Quine [TDoE]:41ff). I do not know whether Quine directly influenced Samuelson. At the time, Quine worked at Harvard and Samuelson worked next door at MIT. Samuelson nowhere explicitly embraces holism. In my view, one should nevertheless understand him as implicitly practicing holism. This takes care of the criticisms that Wong launches against Samuelson's project (Wong [FoPS]:100-121, especially 112-121). It is not an important question, in my view, whether this holistic interpretation correctly represents Samuelson's actual opinions as to 
Let me briefly elucidate why this prediction agrees well with common sense. Given the prices that are mentioned in (23a), the subject in question can, of course, afford the bundle that she actually chooses. However, in this situation she could just as well have afforded the bundle mentioned in (23b), which would have been cheaper. Therefore, from her decision, we can conclude that she prefers the first bundle over the second. But the first bundle was also available to her with the prices mentioned in (23b). Why, then, would she still choose the second bundle in that situation? Obviously, such purchasing behavior would not make much sense. ${ }^{39}$

Another empirically testable consequence from (21) ties into our discussion of Giffen goods. None of the empirically testable conditions that result from the Slutsky equation are sufficient for establishing that some commodity is a Giffen good (see section IV above). However, the Slutsky equation provides a necessary condition for being a Giffen good, and this condition can indeed be empirically tested:

(24) Every Giffen good is an inferior good (i.e. with constant prices and an increasing budget, it would be purchased in smaller quantities). ${ }^{40}$

With (23) and (24), we have two concrete, empirically falsifiable consequences of our microeconomic theory. Thus, the theory can be considered to be an empirical theory.

\section{Criticizing theory or criticizing reality?}

I would now like to ask whether the microeconomists actually behave as if they consider their theory to have empirical content. From the philosophically pleasing conclusion that they could do so, it does not yet follow that their actual practice lives up to that possibility. Whether this is so can be seen in how they deal with empirical refutations of their theory, as for example with an empirical refutation

methodology (which Wong would dispute). It is more important that Samuelson's theory of revealed preferences can be interpreted holistically, and that by doing so, something respectable results. I formulated the result above in the main text without expressly referring to Samuelson because I do not want to get involved in exegetical disputes about the history of ideas.

39 This consideration reflects the intuition behind Samuelson's celebrated "Weak Axiom of Revealed Preference", see Samuelson [PoIi]:370, Varian [IM]:124.

40 See Varian [IM]:143, Kreps [CiMT]:61, as well as Deaton et al [ECB]:45/6. This necessary condition is the contraposition of (and is thus logically equivalent to) the so-called new law of demand. For a formulation, see Varian [IM]:146. 
of sentence (24) just stated. If we want to refute the sentence, we only need to identify one non-inferior Giffen good for a single economic subject. We will, however, go even further and prove this for an entire, representative group of subjects. We will do this in order to take into account the possibility that the sentence to be refuted is not meant to be a strict universal sentence, but should allow some exceptions. Let us consider the following true story:

(25) In the $1980 \mathrm{~s}, \mathrm{MM}$ champagne cost scantly $\$ 5$ dollars per bottle. This brand of champagne was one of the most popular party beverages among non-beer drinking students. There were clearly more bottles of MM champagne consumed when budgets were high, than when budgets were low. (MM champagne was not an inferior good). Then suddenly, the price fell to $\$ 3$ per bottle. (Was the reduction in price accompanied by a reduction in quality? No. In a double-blind test champagne connoisseurs could not distinguish between the older more expensive and the newer cheaper bottles of MM. It was still the same economic commodity, and this was well known). Nevertheless, the reduction in price led to a sinking consumption of MM champagne. Party hosts found it improper to offer cheap champagne, and so the majority switched to Mumm, which cost $\$ 5$ per bottle. In short, MM champagne was a non-inferior Giffen good!

This empirical counterexample may have some bearing on our microeconomic theory, if it claims to be empirical. Yet, microeconomists do not typically react by abandoning the theory in light of our little counterexample. Without much ado, they continue to maintain their theoretically developed proof that all Giffen goods are inferior commodities.

What is going on here? Do we have an indication that the theory does not have anything to do with empirical reality after all? In order to answer this question, first we should clarify which part of the theory does not fit with our counterexample (25). The theory treats the preference relation $\mathrm{R}$ as if it were independent of the price of the respective goods. ${ }^{41}$ However, the counterexample turns on the fact that one and the same commodity becomes intrinsically less attractive as the price falls. Social norms play a role here. Party hosts do not want

41 This independence is not an explicit component of what axioms (22a) and (22b) state. Rather, it results from the form of these axioms. It constitues a basic assumption of our microeconomic theory (see e.g. Hicks [VC]:55). - Couldn't we simply generalize the theory by giving up that basic assumption? No, this would be the end of the theory. We would have to understand the prices as a component of the commodities and to define the preference relation over these extended commodities. Each variation in price would automatically have to change the relata of the preference relation. Thus, the entire architecture of our microeconomic theory would collapse. 
to appear cheap. In other words, champagne is a snob good, and snob goods are partially constituted by their price. ${ }^{42}$

Our microeconomic theory is obviously not intended to apply to such commodities. From a microeconomic perspective, it is irrational to judge one and the same good as having intrinsically less worth when its price sinks, and this perspective has commonsense on its side. We consume champagne by drinking it, not by showing off its price tag (and not by drinking the price tag either). In short, the behavior of the hosts and guests does not indict our microeconomic theory; rather the microeconomic theory indicts the behavior of the hosts and the guests. The theory serves to criticize snobs. ${ }^{43}$

Microeconomists shy away from this normative response to the empirical refutation of their theory. They avoid saying:

(26) If our theory does not apply to the behavior of actual subjects, then so much the worse for them!

The reason for avoiding reactions like (26) is easily understandable. Most microeconomists have read their Popper and are afraid to be seen as selling unfalsifiable tautologies that do not explain anything. ${ }^{44}$ They want to say something that has more content than the following:

Irrational behavior is beyond the scope of our theory. The theory concerns rational subjects. The notion of rationality (concerning purchasing behavior) is defined by our axioms.

42 The last formulation is preferable to the preceding one, as it manages without the (intrinsic) concept of preference, which according to section IX, has no independent content. In the following, I will take the liberty of not always repeating this point, if I may allow myself a manner of expression that should not be taken literally. - Here is another example of how the price independence of intrinsic preferences can fail. Due to superstition, someone could refuse to buy cheese that costs exactly 13 dollars. With this example, one can see that the freshman university students that Blaug cites cannot be right when they learn that: "[...] a rise in the price of a good is followed by a fall in the quantity demanded unless, however, the good in question is either a Giffen or a snob good" ([MoEH]:139, my emphasis). This cannot be right because, as we have just seen, there are more exceptions to the law of demand that can be specified, in addition to the typical Giffen goods (such as potatoes and bad tea) on the one hand, and Snob goods on the other hand. Yet another exception (with far fewer hints of irrationalism) will be discussed in the last section of this essay.

43 Likewise, it can serve to criticize the superstitious purchasing behavior described in the previous footnote.

44 Becker offers an example of this, see [EAtH]:7, 11/2. Instead of postulating an irrational reality whenever there is a contradiction between theory and reality, Becker prefers to postulate psychic costs, whose possible tautological character does not frighten him ([EAtH]:7). Applied to our case, this would have the following bizarre consequence. The monetary price reduction of MM champagne would result in psychic price increases with snobs! 
Indeed, this view would boil down to the blatant tautology directly below, as is repeatedly feared in methodological discussions of economics.

Our theory concerns those subjects to whom our axioms apply. ${ }^{45}$

If a rationalistic interpretation of our microeconomic theory should be more attractive than tautology (28), then something substantial must be added. I would like to conclude my essay with a novel proposal of how this could be accomplished. In the final section, I will suggest that the empirical, descriptive validity of the theory depends on its normative success. ${ }^{46}$ But first, in the next section I will make an excursion into the philosophy of physics that will develop some ideas important to my proposal.

\section{An excursion into autodetermination in physics}

In order to motivate my proposal, I will draw on some considerations from the philosophy of physics that have recently been developed by Oliver Timmer. In his book, Falsifizierbarkeit und Falsifikation im Bereich physikalischer Theorien [Falsifiability and Falsification in the Domain of Physical Theories], Timmer draws attention to a paradoxical aspect of the so-called "structuralist" view of theories (from the Sneed/Stegmüller school). ${ }^{47}$ As Timmer shows in detail, according to the structuralist view, typical physical theories do not make any falsifiable claims about parts of reality that were specified independently of the theory's formulation. If the theory fails in its intended domain of application, then this does not disprove the theory. Rather, it disproves the assumption that the domain in question falls within the theory's intended scope. In short, the theory decides for itself what it is about. It is about that part of reality where it functions. This is Timmer's thesis of autodetermination. ${ }^{48}$

45 Rosenberg claims that such a tautology can be found e.g. in Friedman (see Rosenberg [EMPS]:60/1 and Friedman [MoPE]:8; I present the Friedman citation in footnote 49). In the following two sections, I will demonstrate that one should not allow oneself to be haunted by such a diagnosis.

46 Sven Rosenkranz has called my attention to another possibility for how the theory can be interpreted rationalistically, without allowing it to become a tautology. According to this possibility, the axioms describe rational subjects, but do not offer a definition of rationality. In order to round out the emerging theory, we would have to add an independent definition of rationality. The result would belong to the normative approach to microeconomics. By contrast, according to my suggestion, normative and descriptive elements are merged together. Therefore, my suggestion comes a step closer to the advocates of positive microeconomics.

47 See Timmer [FFiB]:3.2, 4.1. Timmer refers to Stegmüller [TE]/3.

48 See Timmer [FFiB]:4.1.4. 
Thus, we have a situation in the philosophy of physics that resembles the situation at which we had arrived in our considerations regarding microeconomics. ${ }^{49}$ And the worry that concerned us there, also applies here: If Timmer's thesis of autodetermination is correct, does it not follow that physical theories would thereby become contentless tautologies that cannot be empirically refuted? Timmer's answer is both yes and no. Physical theories are not explicitly falsifiable, but it does not follow that they have no content..$^{50}$

Timmer illustrates this paradoxical response with an historical example. ${ }^{51}$ After Galileo stated the law of free fall and claimed that a feather would fall just as quickly as a stone in vacuum, for decades every actual experiment spoke against Galileo's claim. Nevertheless, this did not provide a good reason to give up the theory. Instead, physicists concluded that they had not yet managed to create the experimental conditions applicable to Galileo's theory. Creating a (sufficiently pure) vacuum was beyond their experimental capabilities. Instead of adapting the theory to this awkward situation, the physicists went in just the opposite direction.

They adapted reality to the theory, by perfecting their technological capabilities until Galileo was deemed to have been right after all.52 And this technological capability became an indispensable part of physics. The capability cannot be reduced to knowing the truth of some sentences. It is an instance of knowing how, not of knowing that.

Question: How much longer would the physicists have tolerated their failure to construct the experimental conditions for testing Galileo's statement? There is no clear answer to this question, and that means that Galileo's claim was not falsifiable in a strict sense. In principle, one could have indefinitely continued the search for a vacuum. Of course, that would not have been reasonable. The research program that arose in wake of Galileo's claim would have been aborted

49 Up until now, our considerations fit well with the following claim by Friedman: "[...] theory is to be judged by its predictive power for the class of phenomena which it is intended to 'explain'. " ([MoPE]:8, my emphasis). In the next section, it will turn out that we will proceed from there to a point that Friedman would not have accepted.

50 See Timmer [FFiB], chapter 7.

51 See Timmer [FFiB]:4.1.3, sub-chapter "Autodetermination bei Galilei”.

52 Without limiting it to our present example, Timmer thoroughly discusses these phenomena (see Timmer [FFiB]:4.1.3, sub-chapter "b) Der handlungsorientierende Aspekt des Realisationsprinzips"). He draws on related constructivist ideas that can be found in Hugo Dingler and Holm Tetens (see e.g. Dingler [MP], [ZWPP] and Tetens [WWFB]:33/4, 39/40). 
by incessant failures for centuries. Although Galileo's claim is not strictly falsifiable, it does have some contact to empirical reality.

That Galileo's claim was not a contentless tautology should be obvious. On the one hand, it provided the experimenters with a research program: They were led to search for, or try to create, a vacuum. In this way, the theory helped its advocates produce and discover a domain of application for their theory. On the other hand, in the end the theory did actually apply to reality. At the moment that they had actually succeeded in having the feather and stone fall equally quickly, Galileo was deemed to have been right.

It would be beyond the scope of this paper to present Timmer's considerations about autodetermination in physics to a satisfactory level of detail. Instead, I want to try to apply his considerations to our microeconomic theory. ${ }^{53}$

\section{Microeconomics as a synthesis of norms and descriptions}

Here is the basic idea of my proposal: Just as Galileo's followers had first to manufacture a sufficient vacuum (instead of directly abandoning the theory due to intractable experimental results), the microeconomists must also manufacture the domain of application of their theory. (Instead of directly abandoning it just because champagne-drinking snobs and other irrational people populate the world). In contrast to physics, there is no technological problem. Rather, the microeconomists must convince subjects of the rationality of the theoretical norms that they postulate. ${ }^{54}$ And the microeconomists can accomplish this by criticizing irrational behavior that does not fit their theory.

They must deliver convincing arguments as to why reasonable subjects should not behave in ways prohibited by the theory (such as in the case of champagne-

53 In the methodological discussions of economics, the physicists' concept of vacuum has often been used as a comparison. See for example Friedman [MoPE]:16-19. In Friedman's case, however, only trivial thoughts arise, such as whether it is realistic, and what it means, to assume that we live in an approximate vacuum. Of course, Friedman is right that questions of exactitude arise in economics just as in physics. But did anyone ever doubt this?

54 In order to contrast microeconomics with physics, the emphasis lays on "convince" and on "rationality", not on "norms". This is because the production of a vacuum is likewise a normative process aiming at an ideal, or better, at a standard. But this activity neither aims at an ideal or a standard of rationality, nor must a physicist convince the world to build a vacuum. 
snobs). The respective theory can help them find such arguments (e.g. by providing relevant conceptual means).

But naturally, no one can guarantee in advance that such criticisms will really change the deviant behavior of the subjects - just as Galileo's followers could not be sure whether the required vacuum would ever be available. Here, as there, in the long term it may turn out that the theory in question is unsuitable for describing any domain of application. In that case, at some point the theory must be abandoned.

But the opposite is equally conceivable, and in Galileo's case, it actually occurred - while in the case of microeconomics, we are still waiting to see how it will turn out. If the microeconomists succeed in drawing sufficient attention and adherence to their criticisms of irrational subjects, then this normative-rational success of their theory carries its empirical-descriptive success with it.

Thus, the empirical success of the theory depends on its normative success. In addition, it depends on whether we are prepared to conform to its norms. Nothing forces us. Here is an important difference to physics. Whereas feathers and stones cannot refuse to fall at the same speed under certain circumstances, we can indeed refuse to accept the criticisms of our snobbish (price-dependent) champagne preferences; just as we can refuse to adapt other aspects of the rational behavior that the theory prescribes. This opens a possibility for the opponents of economic thought, which is not open to the opponents of physical thought.

As the opponents of microeconomics are themselves economic subjects, they can behave irrationally (in the sense of microeconomics), and thus, make the domain of application of that theory unattainable. We do not need to invoke informed self-interest or egoism when we wish to decide whether that is advisable. We could also decide by appealing to moral considerations. Perhaps the moral character of this question is not readily apparent with respect to champagnedrinking snobs, but this can be remedied with the help of another example. After all, our theory excludes every (intrinsic) change in preferences on the basis of price changes. Thus, it also excludes the abdication of maximizing behavior in the case of unfair prices (e.g. in the case of prices that the subject traces back to the exploitation of the Third World). 
Whether one wishes to profit from unfair prices is an eminent moral question. It follows that the normative-rational success, and the related empirical success, of our microeconomic theory can even be dependent on moral questions. If microeconomists want to manufacture a domain of application for the theory, then they have to appeal to moral arguments proper. Moreover, these moral arguments would be just as much an indispensable part of their science as the technical production of the vacuum is an indispensable part of physics.

Just as the physics of the law of free fall must have an irreducibly practical part (the laboratory technique), the microeconomic theory under consideration must have an irreducibly normative part - not because it concerns, among other things, the norm-oriented behavior of the subjects, but because their behavior must be normatively led by the theory in order for it to be empirically applicable. ${ }^{55}$

Microeconomics does not offer a hard, value-free description of a reality that would be full of inevitable constraints. And yet, microeconomics offers a description of reality - a description that inextricably contains certain values and norms. ${ }^{56}$ As long as we keep this in mind, we can use it freely, if we want. ${ }^{57}$

55 To my knowledge, it is a new suggestion that the truth of our microeconomic theory can depend on norms (in the sense described). Blaug discusses (and accepts) the possibility of value-free, positive economics from a completely different standpoint ([MoEH]:112-134). His extensive discussion concerns, among other things, (i) the important distinction between methodological norms and moral norms ([MoEH]:113-116), (ii) the question of whether welfare economics can be conducted as a non-normative discipline ([MoEH]:124-128), and (iii) the rejection of defective arguments against the possibility of value-free social sciences in general ([MoEH]:116-121). My suggestion, which is also not covered by Blaug's arguments concerning (iii), is distantly related to Sen's consideration, according to which Samuelson's approach to revealed preferences can fail if the subjects behave morally (Sen [BCoP]:62-66). Sen infers from his considerations that Samuelson's approach is mistaken, and leaves open whether alternative interpretations of the concept of preference could indeed be made independent from the moral behavior of the subject. Against this, I claim that such independence is a chimera. In that respect, my thesis is more radical than related ideas in Critical Theory. I do not claim that a purely positive theory of human society (and respectively its economy) is reactionary or morally dubious (for example because it does not focus on the issue that those societies have developed historically, and thus can be changed). Rather, I claim that such a "purely positive" economic theory must proceed by normatively producing its own domain of application.

56 The fact that in his influential methodology essay, Friedman (without much ado) maintains the exact opposite is not surprising (Friedman [MoPE]:3-7, especially p. 4). When his essay appeared more than a half-century ago, the strict dichotomy between norms and facts belonged to an unquestioned set of beliefs of a whole generation of thinkers. Since the 1970s, that was opposed by the thesis of the inextricable entanglement of facts and norms. (See Williams [ELoP]:140-141; Murdoch [IoP]:22-23, 42; McDowell [AMRH]:21; Putnam [RTH]:139-141; Putnam $[\mathrm{CoFV}])$. This thesis originally applied to moral language, but its scope of application has continued to expand dramatically. The first corresponding adumbrations in economics can be found, to my knowledge, in Putnam. Of course, economics is not the only scientific discipline in which facts inextricably mix with values. Another such discipline is 


\section{Literature}

Albert, Hans [MP]: "Modell-Platonismus. Der neoklassische Stil des ökonomischen Denkens in kritischer Beleuchtung". In Topitsch (ed) [LS]: 406-434. [Appeared first 1963].

Becker, Gary S. [EAtH]: The Economic Approach to Human Behavior. (Chicago: The University of Chicago Press, 1976).

Blaug, Mark [MoEH]: The Methodology of Economics or How Economists Explain. (Second Edition. Cambridge: Cambridge University Press, 1992). [Appeared first 1980].

Davidson, Donald [IiTI]: Inquiries into truth and interpretation. (Oxford: Clarendon Press, 1984).

Davidson, Donald [RI]: "Radical interpretation". In Davidson [IiTI]:125-139. [Appeared first 1973].

Deaton, Angus / Muellbauer, John [ECB]: Economics and Consumer Behavior. (Cambridge: Cambridge University Press, 1994). [Appeared first 1980].

Dingler, Hugo: Der Zusammenbruch der Wissenschaft und der Primat der Philosophie. (München: Reinhardt, 1926).

Dingler, Hugo: Die Methode der Physik. (München 1938).

Friedman, Milton: [EiPE]: Essays in Positive Economics. (Chicago: The University of Chicago Press, 1953).

Friedman, Milton: [MoPE]: "The Methodology of Positive Economics". In Friedman [EiPE]: 3-43.

Hempel, Carl Gustav / Oppenheim, Paul [SiLo]: "Studies in the logic of explanation". Philosophy of Science 15 (1948), pp. 135-75.

Hicks, J. R. [VC]: Value and Capital. (Oxford: Clarendon Press, 1939).

Inhetveen, Rüdiger / Kötter, Rudolf (eds) [FnP]: Forschung nach Programm? Zur Entstehung, Struktur und Wirkung wissenschaftlicher Forschungsprogramme. (München: Wilhelm Fink Verlag, 1994).

Kreps, David M. [CiMT]: A Course in Microeconomic Theory. (New York: Harvester Wheatsheaf, 1990).

historiography, which I tried to elaborate through writings on the Kosovo war, see Müller [WWSü], section IV to VII, and [RP]:60-66.

57 This essay developed out of a lecture I gave in 1995 at the Faculty of Economics at GeorgAugust Universität, Göttingen. Its final form is due to comprehensive critiques by the editors of this symposion, as well as by two anonymous referees. I would like to thank them for their suggestions, and the participants of the original discussion in Göttingen, most especially Günter Gabisch. I also thank Jürgen Müller, Sven Rosenkranz, Thomas Schmidt and Holm Tetens for suggestions. Finally, I thank Eric Oberheim for translating this essay into English. 
Lipsey, Richard G. / Rosenbluth, Gideon. [CtNT]: "A contribution to the new theory of demand: A rehabilitation of the Giffen good". Canadian Journal of Economics Vol 4 No. 2 (May 1971), pp. 131-163.

McDowell, John [AMRH]: "Are moral requirements hypothetical imperatives?" Proceedings of the Aristotelian Society. Supplementary Volume LII (1978), pp. 12-29.

Meggle, Georg (ed) [EoHI]: Ethics of Humanitarian Interventions. (Franfurt/Lancaster: Ontos Verlag, 2004).

Meggle, Georg (ed) [HI]: Humanitäre Interventions-Ethik. Was lehrt uns der Kosovo-Krieg? (Paderborn: Mentis, 2004).

Müller, Olaf [AEE]: Arten ethischer Erkenntnis. Plädoyer für erkenntnistheoretischen Respekt vor der Moral. (Forthcoming; Mentis, Paderborn, 2007).

Müller, Olaf [CTSW]: "Can they say what they want? A transcendental argument against utilitarianism". The Southern Journal of Philosophy XLI No. 2 (June 2003), pp. 241-259.

Müller, Olaf [RP]: "Reconstructing pacifism. Different ways of looking at reality". In Meggle (ed) [EoHI]:57-80.

Müller, Olaf [WWSü]: "Was wissen Sie über Kosovo? - Fallstudie über Pazifismus, Propaganda und die Verquickung von Fakten mit Werten". In Meggle (ed) [HI]:53-90.

Murdoch, Iris [IoP]: "The idea of perfection". In Murdoch [SoG]:1-45.

Murdoch, Iris [SoG]: The sovereignty of good. (London: Routledge \& Kegan Paul, 1970).

Putnam, Hilary [CoFV]: The collapse of the fact/value dichotomy and other essays. (Cambridge / Mass.: Harvard University Press, 2002).

Putnam, Hilary [MFoR]: The many faces of realism. (LaSalle: Open Court, 1987).

Putnam, Hilary [RTH]: Reason, truth and history. (Cambridge: Cambridge UP, 1981).

Puu, Tõnu [SRoR]: "Some reflections on the relation between economic theory and empirical reality". Swedish Journal of Economics LXIX No 2 (June 1967), pp. 85-114.

Quine, Willard Van Orman [fLPo]: From a logical point of view. (Cambridge / Mass.: Harvard UP, second edition, revised, 1961). [Appeared first 1953].

Quine, Willard Van Orman [PoT]: Pursuit of truth. (Cambridge / Mass.: Harvard UP, 1990, revised edition 1992).

Quine, Willard Van Orman [TDoE]: "Two dogmas of empiricism". In Quine [fLPo]:20-46. [Appeared first 1951]. 
Quine, Willard Van Orman [WO]: Word and object. (Cambridge / Mass.: MIT Press, 1960).

Rosenberg, Alexander [EMPS]: Economics - Mathematical Politics or Science of Diminishing Returns? (Chicago: The University of Chicago Press, 1992).

Samuelson, Paul A. [CSPo]/I: The Collected Scientific Papers of Paul A. Samuelson. Volume I. (Edited by Stiglitz, Joseph E.) (Cambridge/Massachusetts: The M.I.T. Press, 1991). [Appeared first 1966].

Samuelson, Paul A. [CTiT]: "Consumption Theory in Terms of Revealed Preference". In Samuelson [CSPo]/I: 64-74. [Appeared first 1948. My quotations refer to the original page numbers].

Samuelson, Paul A. [FoEa]: Foundations of Economic Analysis. (Enlarged edition. Cambridge/Massachusetts: Harvard University Press, 1983). [Appeared first 1947].

Samuelson, Paul A. [NoPT]: "A Note on the Pure Theory of Consumer's Behaviour". In Samuelson [CSPo]/I: 3-14. [Appeared first 1938. My quotations refer to the original page numbers].

Samuelson, Paul A. [PoIi]: "The Problem of Integrability in Utility Theory". In Samuelson [CSPo]/I: 75-105. [Appeared first 1950. My quotations refer to the original page numbers].

Sen, Amartya [BCoP]: "Behaviour and the Concept of Preference". In Sen [CWM]: 54-73. [Appeared first 1973].

Sen, Amartya [CWM]: Choice, Welfare and Measurement. (Cambridge/Massachusetts: Harvard University Press, 1982).

Stegmüller, Wolfgang [TE]/1: Theorie und Erfahrung. Erster Halbband. (Probleme und Resultate der Wissenschaftstheorie und Analytischen Philosohie, Band II.1). (Berlin: Springer, 1970).

Stegmüller, Wolfgang [TE]/3: Theorie und Erfahrung. Dritter Teilband. Die Entwicklung des neuen Strukturalismus seit 1973. (Probleme und Resultate der Wissenschaftstheorie und Analytischen Philosophie, Band II). (Berlin: Springer, 1986).

Tetens, Holm [WWFB]: "Welchen wissenschaftstheoretischen Fortschritt bringt das Konzept der Forschungsprogramme?" In Inhetveen et al (eds) [FnP]:25-42.

Timmer, Oliver [FFiB]: Falsifizierbarkeit und Falsifikation im Bereich physikalischer Theorien: Eine Diskussion auf strukturalistischer Grundlage. (Inauguraldissertation am Fachbereich Philosophie und Geisteswissenschaften der Freien Universität Berlin, 2004).

Topitsch, Ernst (ed) [LS]: Logik der Sozialwissenschaften. (Berlin: Kiepenheuer \& Witsch, 1965). 
Varian, Hal R. [IM]: Intermediate Microeconomics: A Modern Approach. (Third Edition. New York: W. W. Norton, 1993). [Appeared first 1987].

Varian, Hal R. [MA]: Microeconomic Analysis. (Third Edition. New York: W. W. Norton, 1992). [Appeared first 1978].

Williams, Bernard [ELoP]: Ethics and the limits of philosophy. (Cambridge / Mass.: Harvard University Press, 1985).

Wittgenstein, Ludwig [PU]: Philosophische Untersuchungen. In Wittgenstein [W]/1:225-618. [Appeared first 1953].

Wittgenstein, Ludwig [W]/1: Werkausgabe Band 1. (Frankfurt: Suhrkamp, 1984).

Wong, Stanley [FoPS]: The Foundations of Paul Samuelson's Revealed Preference Theory: A Study by the Method of Rational Reconstruction. (London: Routledge \& Kegan Paul, 1978). 